\title{
QUEEN'S
UNIVERSITY
BELFAST
}

\section{EMAS and ISO 14001 in the German industry - complements or substitutes?}

Neugebauer, F. (2012). EMAS and ISO 14001 in the German industry - complements or substitutes? Journal of Cleaner Production, 37, 249-256. https://doi.org/10.1016/j.jclepro.2012.07.021

Published in:

Journal of Cleaner Production

Document Version:

Peer reviewed version

Queen's University Belfast - Research Portal:

Link to publication record in Queen's University Belfast Research Portal

\section{Publisher rights}

This is the author's version of a work that was accepted for publication in Journal of Cleaner Production. Changes resulting from the publishing process, such as peer review, editing, corrections, structural formatting, and other quality control mechanisms may not be reflected in this document. Changes may have been made to this work since it was submitted for publication. A definitive version was subsequently published in Journal of Cleaner Production, VOL 37, 12/2012

\section{General rights}

Copyright for the publications made accessible via the Queen's University Belfast Research Portal is retained by the author(s) and / or other copyright owners and it is a condition of accessing these publications that users recognise and abide by the legal requirements associated with these rights.

\section{Take down policy}

The Research Portal is Queen's institutional repository that provides access to Queen's research output. Every effort has been made to ensure that content in the Research Portal does not infringe any person's rights, or applicable UK laws. If you discover content in the Research Portal that you believe breaches copyright or violates any law, please contact openaccess@qub.ac.uk. 


\section{Accepted Manuscript}

EMAS and ISO 14001 in the German industry - complements or substitutes?

Friederike Neugebauer

PII: S0959-6526(12)00359-9

DOI: $\quad$ 10.1016/j.jclepro.2012.07.021

Reference: JCLP 2976

To appear in: Journal of Cleaner Production

Received Date: 19 October 2011

Revised Date: 11 June 2012

Accepted Date: 9 July 2012

Please cite this article as: Neugebauer F, EMAS and ISO 14001 in the German industry - complements or substitutes?, Journal of Cleaner Production (2012), doi: 10.1016/j.jclepro.2012.07.021.

This is a PDF file of an unedited manuscript that has been accepted for publication. As a service to our customers we are providing this early version of the manuscript. The manuscript will undergo copyediting, typesetting, and review of the resulting proof before it is published in its final form. Please note that during the production process errors may be discovered which could affect the content, and all legal disclaimers that apply to the journal pertain. 


\section{EMAS and ISO 14001 in the German Industry - Complements or Substitutes?}

Author: Friederike Neugebauer, f.neugebauer@alumni.lse.ac.uk. Queen's University Management School, Belfast.

Phone: +49 (0)176 668 13723. Postal: Schwabstr. 6, 70197 Stuttgart, Germany

Abstract: The two environmental management system (EMS) standards EMAS and ISO 14001 have been available in Europe for the last 15 years. ISO 14001 has been taken up at a much larger scale but many firms in the German automotive and engineering industry have certified their EMSs according to both standards. Two research questions are addressed: (i) What explains why companies adopt both EMAS and ISO 14001? (ii) Are EMAS and ISO 14001 complements or substitutes? Based on 21 interviews with industrial and institutional representatives, this study finds that, first, the two standards are adopted for completely different reasons: while ISO 14001 is often done as a response to external pressure, EMAS tends to be motivated internally. Second, it is argued that EMAS and ISO 14001 are likely in a situation of direct competition at present which may well turn into complementarity in the future.

Key words: environmental management systems; standards; EMAS; ISO 14001; complementarity; competition. 


\section{INTRODUCTION}

Since the 1990s, new environmental policy instruments have developed which encompass a range of market-based instruments and voluntary regulation. Environmental management systems (EMS) belong to the 'more flexible policy instrument(s)' (Zito and Egan, 1998) that arose in the wake of what Banerjee has termed 'corporate environmentalism', i.e. the 'the recognition and integration of environmental concerns into a firm's decision-making process' (Banerjee, 2002; see also Hillary and Thorsen, 1999). The mid-90s saw the emergence of the two EMS standards that remain dominant until today: the European Eco-Management and Audit Scheme (EMAS) and the International Organization for Standardization's ISO 14001. Both standards are comparatively successful in the German automotive and engineering industry which makes Germany an interesting place for researching their relationship. Two research questions are addressed in this study. First,

(i) what explains why companies adopt both EMAS and ISO 14001?

In the interviews that were conducted, this was addressed by asking what motivated the adoption of EMAS and ISO 14001, respectively, and how the two decisions were related at the firm. The second research question is which of two hypotheses can be confirmed:

(ii) EMAS and ISO 14001 are complementary, i.e. implementation of one makes implementation of the other more likely (complementarity hypothesis).

(iii)EMAS and ISO 14001 are substitutes, i.e. companies find one more compelling than the other and do not have an incentive to implement both (substitution hypothesis).

It is found that the two standards are adopted for completely different reasons: while ISO 14001 is often done in response to external pressure, EMAS tends to be motivated internally. Further, it appears that EMAS and ISO 14001 are likely in a situation of direct competition at present which may well turn into complementarity in the future. The following Section is to establish the context of existing research that helps understand EMS standards and their adoption. From the existing literature, expectations are deduced about the motivations of firms to get their EMSs certified and about the relationship between the two standards. It will also show the gaps in the existing literature. The third Section describes the chosen methodology which combines a deductive literature review and an inductive, qualitative 
approach based on semi-structured expert interviews. The findings are presented in Section 4; Section 5 discusses them and shows the contribution of this study. The conclusion summarises the main points and concludes with questions that may be interesting for further research.

\section{UPTAKE AND DIFFUSION OF STANDARDS}

This Section reviews the literature relevant for understanding what motivates adoption of the two standards and their relation. First, the two EMS standards ISO 14001 and EMAS are reviewed and put in context of the standards literature and the literature on innovation diffusion. Second, external and internal factors identified by previous researchers to motivate environmental activities and adoption of standards at firms are discussed. The last part looks at the expectations derived from this literature and the gaps in it.

\subsection{TwO EMS STANDARDS}

Standards have been defined as 'pieces of general advice offered to a large number of potential adopters' (Brunsson and Jacobsson, 2000b). Standards are voluntary but can act as a form of regulation or governance, especially when they become institutionalised. Indeed, they can become coercive when third parties demand organisations to comply (Brunsson and Jacobsson, 2000a). If standards are adopted by a critical mass of firms, adoption becomes self-enforcing with the possible consequence that standards get locked-in.

EMAS and ISO 14001 are examples for such 'pieces of general advice', both serving the purpose of helping companies to implement EMSs that fulfil certain criteria. There are three major differences between the two. First, ISO 14001 is managed by the International Organization for Standardization (ISO) and its equivalents at the national level, such as the German DIN. ISO 14001 certification is available from private accreditation organisations, such as the TÜV in Germany. In contrast, EMAS has been created by the European Commission which manages it in cooperation with the competent bodies at the national level. Thus, EMAS is an instrument of public institutions whereas ISO 14001 certification is sold by private accreditation providers. Second, EMAS' requirements go beyond those of ISO 14001. For instance, a firm is required to continuously improve its environmental performance under EMAS and to publish an environmental report to demonstrate this improvement. ISO 14001 only requires continuous improvement of the management system. Lastly, EMAS is only available in the EU and has been validated less than 8,000 times (EMAS, 2010a). By contrast, 
over 188,000 ISO 14001 certificates have been issued worldwide, of which almost 48,000 in Europe (ISO, 2008).

***insert fig. 1 about here $* * *$

Figure 1 shows that in Europe, ISO 14001 is adopted at a much larger scale than EMAS. Whether this evidence supports the substitution or complementarity hypothesis is not straightforward since EMAS numbers are not declining as ISO 14001 numbers are increasing (Perkins and Neumayer, 2004), but they are not proportionally rising either.

Rogers' diffusion of innovations model (Rogers, 1995) describes the adoption of dominant innovations as following an S-shaped curve. The idea is that new innovations are taken up by a small number of innovators at first but once the number of adopters reaches a certain threshold, adoption becomes self-sustaining and fast-increasing: the curve becomes steeper. Growth rates are expected to slow down again towards saturation when the curve levels off. If EMS standards are understood as process- or organisational innovations (Franken and Franken, 2011) Rogers' model may help analyse their adoption curves. ISO 14001 might follow such a curve (the larger curve in figure 2), assuming that the turning point is yet to be reached. EMAS saw a decline in registrations in the early 2000s but numbers have gone up again when it became easier for smaller enterprises and non-industrial entities to get validated. Hence, the EMAS adoption rate among big industrial firms could look like the smaller curve in figure 2 which is being crowded out by the bigger (ISO 14001) curve if hypothesis (iii) holds true. In Germany, EMAS validations are slightly decreasing every year while ISO 14001 adoption still rises (DIHK, 2010; ISO, 2005, 2008). If the standards act as complements however, as suggested in hypothesis (ii), the two adoption curves should run more or less parallel.

$* * *$ insert figure 2 about here $* * *$

\subsection{DRIVERS OF STANDARDS ADOPTION}

Many authors have distinguished external and internal factors driving corporate decisions about standard implementation. In the following, this distinction will be maintained although it should be noted that internal and external factors are likely to interact (Perkins and Neumayer, 2010).

\subsubsection{EXTERNAL FACTORS}


The most relevant external factors for this study are (1) the organisational field, (2) the institutional environment of a firm, and (3) complementary standards such as ISO 9001.

The organisational field in which a firm operates, i.e. its competitors and partner firms, influences corporate decisions and strategies (Bansal and Bogner, 2002; O'Neill et al., 1998). Institutional theory is helpful to illuminate external factors influencing corporate decision making. Müller et al. (2009) show that firms often use standards such as ISO 14001 to gain legitimacy, which is supported by Schaefer (2007) who also shows that institutional forces such as customer requirements and public image are increasingly important drivers for EMS adoption. Also Delmas (2001) suggests the extent to which companies rely on their reputation as an important driver. DiMaggio and Powell's isomorphism framework (1983) explains how organisations in a field put each other under pressure and Oliver (1991) shows how companies may react to this pressure. Once a field has reached a certain degree of integration, companies stop basing their decisions on efficiency gains or competitive advantage but instead react to mimetic, normative, and coercive pressure. The result is that organisations start to resemble each other more and more which might be particularly so for organisations with similar strategic goals (Greve, 1998). In the same vein, Rogers (1995) finds that high homophily in a social system increases the adoption rate.

Second, the institutional environment in which a company is embedded is an important influence on corporate decisions. Companies want to gain legitimacy and are under pressure from institutions and stakeholders (Bansal and Bogner, 2002; Delmas and Montiel, 2008; Kollman and Prakash, 2002; Neumayer and Perkins, 2004; Potoski and Prakash, 2004). Also the kind of business-government relations and political traditions in a firm's host country are important (Delmas and Terlaak, 2001; Kollman and Prakash, 2001; Moon and DeLeon, 2005): According to Bracke and Albrecht (2007), Germany's corporatist and statist polity model resulted in strong governmental support for EMS certification compared to other European countries, thereby providing for a conducive environment for EMAS and ISO 14001 (see also Kollman and Prakash, 2002). Regulatory incentives in the form of regulatory relief are expected to have a positive influence on the uptake of EMS standards (Glachant, 2001; Wätzold et al., 2001).

Finally, many scholars point to the facilitating effects of established standards, such as the quality standard ISO 9001 (Moon and DeLeon, 2005; Perkins and Neumayer, 2004; Potoski 
and Prakash, 2004). Since standardisation is globally on the rise, firms may implement standards in order to be prepared for future standards (Corbett and Kirsch, 2000).

\subsubsection{INTERNAL FACTORS}

The two most important internal drivers suggested in the literature are (1) the availability of win-win possibilities (or perception thereof), and (2) leadership by individuals in the management.

Corporate decisions for standards can be interpreted as strategic decisions aimed at gaining comparative advantage (Epstein and Roy, 1998; Hoffman, 2001; Kollman and Prakash, 2002). This is in line with concepts such as Factor Five (von Weizsäcker, 2010) and ecoefficiency (Schaltegger and Burritt, 2000) which stress the ecological and financial gains that are expected from increased efficiency. Also Porter and van der Linde argue that environmental investments are often economically profitable and that environmental regulation tends to produce innovation offsets (Porter and van der Linde, 1999, see also Holliday et al., 2002). In contrast, Kollman and Prakash (2002) and Dyllick (2007) suggest that low-hanging fruits may soon be gone and that efficiency gains have been mostly exploited. Others stress that trade-offs are the rule rather than the exception (Hahn et al., 2010) and that eco-efficiency is insufficient for obtaining sustainability (Dyllick and Hockerts, 2002; Young and Tilley, 2006). As will be shown below, the perception of how widely win-win opportunities are available depends mostly on the corporate culture.

Other scholars argue that standard adoption may enable companies to pre-empt or avoid stringent regulation (Delmas and Terlaak, 2001; Khanna and Anton, 2002; Kollman and Prakash, 2002; Maxwell et al., 2000). Further, the importance of individual leaders for EMS certification at firms (Bansal, 2003). In sum, it appears that the external factors that may influence a company's decision to implement EMS standards have been researched widely whereas the literature has spread itself thinner with regards to internal factors. How exactly the decisions about adoption of EMAS and ISO 14001 may be influenced by internal factors is still unclear. Furthermore, it remains uncertain whether the decisions about the two standards are influenced by the same factors, and why companies would choose to implement both standards.

\subsection{COMPLEMENTS OR SUBSTITUTES?}


ISO 14001 and EMAS are interpreted as complementary by some (Delmas, 2002; Delmas and Montiel, 2008) and as competing by others (Bracke and Albrecht, 2007). The authors advocating complementarity stress that EMAS implementation triggers a process of learning which eventually facilitates certification according to ISO 14001, and vice versa. Following this argument, one would conclude that ISO 14001 and EMAS complement each other if firms experience a learning process after certifying their EMS according to one of the two standards. This would mean that the two standards reinforce each other, similar to the reinforcing influence of ISO 9001 on EMS standards claimed by Moon and DeLeon (2005), Perkins and Neumayer (2004), and Potoski and Prakash (2004).

On the other hand, ISO 14001 has clearly outnumbered EMAS in Europe, only at a different speed in different countries (Bracke and Albrecht, 2007). The substitution hypothesis (iii) is backed up more by statistics than by theory. Since this study particularly focuses on firms that have both standards implemented, the substitution hypothesis would be supported if some sort of temporal dynamic was found, e.g. that companies with both standards tend to have EMAS still in place as a residue but are now focussing their efforts on ISO 14001.

It appears that the answer to the second research question cannot be derived from the literature either. Answering the two research question thus requires empirical investigation.

\section{METHODOLOGY}

In a first step, this study has analysed the relevant literature on standards and their diffusion, on innovation uptake and the motivational factors influencing corporate decisions, as well as the existing research on ISO 14001 and EMAS (Section 2). However, existing literature fails to explain the relationship between the two standards and the factors that motivate implementation of both. In order to help fill this gap, a qualitative approach is chosen as a second step. Germany is by far the country with the highest total EMAS uptake (UBA, 2011), yet it also has the seventh-highest number of ISO 14001 certifications worldwide and the fourth-highest in Europe (ISO, 2008). Since there is no clear dominance of one standard over the other with many firms adopting both standards, it is a good place to investigate the relation of ISO 14001 and EMAS.

In total, 21 semi-structured expert interviews with 15 corporate and six institutional representatives were conducted. The firms were chosen based on the following criteria: they are all internationally operating companies, either in the automotive sector or in the 
engineering industry (part suppliers). This industry is chosen because of its environmental relevance and its dominant position in the German economy (the manufacturing industry creates roughly $25 \%$ of German GDP DESTATIS, 2012 and about 16\% of German emissions UBA, 2010). All firms are certified according to both ISO 14001 (at most sites) and EMAS (at one site at least), except two counter-examples that had decided to discontinue EMAS. Out of the 100 biggest firms (by employees) in the EMAS EU Register (EMAS, 2010b), 56 are manufacturing companies. Since EMAS lists every validated site, these 56 sites correspond to 30 companies which were contacted and of which 15 agreed to participate. The institutional interviewees were found through online research or were recommended in the earlier interviewees. They represent the BMU (Federal Environment Ministry), DAU (German accreditation association), DIHK (German Chamber of Commerce Association, competent body for EMAS), ISO, TÜV Nord (one of the larger accreditation firms), and the UGA (German EMAS Advisory Board). The interviews took place between April and August, 2010, and were conducted in German, 12 of them in person and nine on the phone, taking between 60 and 90 minutes. The interview protocols were sent to the interviewees if they had agreed to counter-check them (five interviewees did). All quotes were translated by this author. After about half of the interviewees asked to remain anonymous so they could speak more openly, it was decided to keep all interviewees anonymous.

Semi-structured interviews seemed most appropriate to better understand the corporate 'insider' perspective on a topic that has not been covered widely in the literature. Another possible technique would have been a quantitative analysis of stated preferences for one or the other EMS. However, this would have meant rather constraining questionnaires. The objective of this research is to understand nuanced differences in corporate behaviour. Since there is not one single hypothesis to confirm or reject, it seemed critical to be as open as possible. For such an exploratory research interest, a qualitative method that allows for conversation and dialogue is most appropriate (Kvale, 1996).

This study is limited in time frame and scope, and will not allow for broad generalisations. It is an exploratory study based on a small sample and only covers transnational corporations of the German automotive and engineering industry. Furthermore, only companies listed in the EMAS EU Register (2010) are considered, thus companies that never adopted EMAS are left out of the picture. 


\section{Findings}

This Section is structured in three parts, corresponding to the three parts of the interview question catalogue, covering (1) general environmental policy and EMS at the companies, (2) the external and internal motivations for implementing/maintaining each standard, and (3) the interaction of ISO 14001 and EMAS and the interviewees' expectations of future developments. While the first set of questions served to better understand the context of each company, the second and third part sought explanations for the first and second research question, respectively. The question catalogue is available from the author on request.

\subsection{A TYPOLOGY OF CORPORATE CULTURES}

The statements from the first set of questions served to clarify the corporate contexts, but they were also analysed and compared regarding explicit and implicit information about corporate culture. From this analysis, three categories of corporate culture emerged. Six firms were classified as part of the EMAS fan community (adopting an expression by interviewee no. 2), these were firms that had an internal motivation to do EMAS and justified it with ethical arguments. Here, EMAS is seen as the 'right system to have'. The second group of rational calculators comprises firms that have implemented EMAS at a few sites but might discontinue it on cost grounds. EMAS did not fulfil their expectations or was a redundant effort in the presence of ISO 14001. These firms might have ISO 14001 certificates because their clients require them, and might have EMAS because they got 'stuck' with it. The third group is in between the first two and contains firms that believe in the win-win discourse. These firms are willing to walk an extra mile for the environment because they think it is the right thing to do. Yet, they expect economic benefits from it as well. Hence, they are more likely than the fan community to discontinue EMAS but not as focused on economic benefit as the rational calculators.

Table 1. A typology of corporate cultures

\begin{tabular}{|c|c|c|}
\hline $\begin{array}{l}\text { Fan community } \\
\text { (Interviews no. } 5 ; 8 ; 15 ; 16 ; \\
19 ; 20)\end{array}$ & $\begin{array}{l}\text { Rational calculators } \\
\text { (Interviews no. } 1 ; 4 ; 6 ; 9 ; \\
11 ; 14 ; 15)\end{array}$ & $\begin{array}{l}\text { Win-win proponents } \\
\text { (Interviews no. } 3 ; 6 ; 7 ; 9 ; \\
10 ; 14 ; 20)\end{array}$ \\
\hline $\begin{array}{l}\text { Have EMAS because it is } \\
\text { seen as 'the right system to } \\
\text { have' }\end{array}$ & $\begin{array}{l}\text { Got 'stuck' with EMAS; } \\
\text { would abandon it if it wasn't } \\
\text { for the reputational damage }\end{array}$ & $\begin{array}{l}\text { Have EMAS because } \\
\text { environmental and financial } \\
\text { benefits are expected }\end{array}$ \\
\hline
\end{tabular}




\begin{tabular}{|l|l|l|}
\hline $\begin{array}{l}\text { ISO 14001 is not much extra } \\
\text { effort }\end{array}$ & $\begin{array}{l}\text { Have ISO 14001 because it is } \\
\text { mandated }\end{array}$ & $\begin{array}{l}\text { ISO } 14001 \text { because } \\
\text { environmental and financial } \\
\text { benefits are expected }\end{array}$ \\
\hline
\end{tabular}

Naturally, there is some overlap between these categories. However, distinguishing the fan community and the win-win firms makes sense since the former are mainly motivated by ethical considerations whereas the latter in addition expect a financial return. The rational calculators put the highest priority on economic costs and benefits when it comes to environmental management as opposed to the win-win proponents that are motivated by ethical considerations but still expect a significant financial return as well.

\subsection{DRIVERS OF STANDARD ADOPTION}

The interviews show that ISO 14001 has become institutionalised to an extent where it is de facto mandatory whereas EMAS is only implemented by firms that have an internal motivation to do so. The decision about EMAS is often made at the site level whereas ISO 14001 is decided about at the highest corporate level. In the following, driving factors are presented in the order of decreasing relevance as described by the interviewees.

\subsubsection{FACTORS INFLUENCING THE IMPLEMENTATION OF EMAS}

Almost all interviewees said that internal factors had been much more important than external factors in motivating EMAS validation. First, the majority of interviewees described a corporate culture that was conducive to EMAS (Interviews no. 3; 5-9; 14-16; 19-20). When EMAS became available in 1993, most of the interviewed companies were among the first to seek EMAS validation because they wanted a credible certification of their EMS which was in many cases implemented at the site level. When ISO 14001 became available in 1996, it was rather easy for these firms to get certified. Those that started EMAS a few years later when both standards were available often decided to opt for the 'better system' - many interviewees referred to a corporate tradition to go beyond minimum requirements (Interviews no. 4-5; 7-8; partly 9; 14-16). As one interviewee put it, 'we even hand out Christmas gifts to children - that's just something that matters to us' (Interview no.14). On the other hand, a culture requiring measures beyond EMS standards was often described too (Interviews no. 1; $4 ; 8 ; 14 ; 16 ; 20$; partly $9 ; 11)$. These companies often have tangible environmental objectives beyond the requirements of both standards, such as reduction targets concerning energy 
consumption or emissions. They criticise that the continuous improvement of environmental performance required by the EMS standards is only a relative goal and could be in the 'subnano range' (Interview no. 1).

The second internal factor was observed less frequently but seemed of high importance when it occurred: the influence of particular individuals. These were either dedicated environmental managers who went out of their way to set up the EMS (Interviews no. 3;6;8) or members of the owning families who used their positions on the board of directors to advance the environmental policy in favour of EMAS and other activities (Interviews no. 5; 8).

The one important external factor was reputation. Many firms planned on using the EMAS environmental statement for stakeholder communication but learned over the years that there was hardly any interest. As interviewee no. 6 put it, 'those interested parties simply don't exist!'. However, especially the more visible and reputation-aware firms find it entirely impossible to abandon EMAS, even if this made sense economically, because of the expected damage to their reputation (Interviews no. 9-10;15; 19-20). Furthermore, sustainability ratings often rank EMAS-validated firms higher which affects the firms' reputation (Interviews no. 4- 5; 15) and their access to outside capital (Interviews no. 5; 14). The reputational effect of EMAS seems to work backwards: although reputation cannot be gained, keeping EMAS avoids reputational damage.

Many interviewees described how German authorities promised regulatory relief in the 1990s but failed to fulfil the expectations they had created. Nonetheless, almost all interviewees (except no. 14) said that regulatory relief did not play a major role. Some stated that EMAS had improved their relationship with the authorities who generally had a higher level of trust in EMAS-validated firms (Interviews no. 7; 19).

Almost all interviewees made it very clear that they were not exposed to any external pressure from the public, the market, or competitors in their decision on EMAS. The hope to gain reputation also influenced the decision making but was largely disappointed which makes some firms feel that they got stuck with EMAS. Rather, the internal factors, namely corporate culture and influential managers, were the most important drivers for EMAS adoption.

\subsubsection{FACTORS INFLUENCING THE IMPLEMENTATION OF ISO 14001}

In the case of ISO 14001, internal factors played a minor role compared to external ones. In order to appear progressive and to respond to mounting public pressure, the German 
Association of the Automotive Industry (VDA) started encouraging the car industry in the early 1990s to introduce EMSs and require them from their suppliers (Interviews no. 9; 15). The car producers are often dominant clients and their suppliers can hardly afford to lose these contracts, and the same is true for the suppliers of their suppliers (Interviews no. 10;15). This way ISO 14001 has become a basic requirement for business relations, comparable to the quality management standard ISO 9001. The pressure to get ISO 14001-certified was externally motivated in all companies that were interviewed, be it by the VDA decision or client requirements, i.e. by pressure from the organisational field. The decision was usually made at the highest level and implemented top-down.

To sum up, corporate decisions for EMAS tend to be driven by internal factors such as a specific corporate culture and the influence of dedicated managers. In contrast, ISO 14001 appears to be motivated by external factors, i.e. client requirements that go back to the VDA decision in the 1990s which itself was driven by mounting external pressure on the automotive industry.

\subsection{FUTURE TRENDS}

Two questions were discussed in the third part of the interviews: first, what is the future of EMAS and ISO 14001? Second, will one standard dominate or will they both be replaced by something new? During interviews, three future scenarios came up repeatedly for each standard, respectively. These scenarios help weigh the complementarity hypothesis (ii) against the substitution hypothesis (iii) but they were also used to gain insights into the corporate cultures of the interviewed firms. The more EMAS-enthusiastic interviewees, for instance, tended to be less pessimistic about its future.

\subsubsection{THREE SCENARIOS FOR EMAS}

Table 2. Future scenarios for EMAS and ISO 14001

\begin{tabular}{|l|l|l|lr|}
\hline $\begin{array}{l}\text { Supported } \\
\text { hypothesis }\end{array}$ & Future scenarios & $\begin{array}{l}\text { Supported by } \\
\text { interview } \\
\text { statements }\end{array}$ & $\begin{array}{l}\text { Supported by } \\
\text { literature }\end{array}$ \\
\hline $\begin{array}{l}\text { Complementarity } \\
\text { hypothesis (ii) }\end{array}$ & $\begin{array}{l}\text { EMAS will become the } \\
\text { premium standard }\end{array}$ & $2 ; 8 ; 9 ; 16-18 ; 20$ & $\begin{array}{l}\text { Delmas, 2002; } \\
\text { Delmas and } \\
\text { Montiel, 2008 }\end{array}$ \\
\hline
\end{tabular}




\begin{tabular}{|l|l|l|l|}
\hline $\begin{array}{l}\text { Substitution } \\
\text { hypothesis (iii) }\end{array}$ & $\begin{array}{l}\text { EMAS will die while ISO } \\
\text { will become the one EMS } \\
\text { standard }\end{array}$ & $\begin{array}{l}1 ; 4 ; 6 ; 9-11 ; 13 ; \\
16-17 ; 19\end{array}$ & $\begin{array}{l}\text { Bracke And } \\
\text { Albrecht, 2007 }\end{array}$ \\
\hline Independence & $\begin{array}{l}\text { EMAS will be the standard } \\
\text { for SMEs and non-industrial } \\
\text { sectors }\end{array}$ & $1,5,17,21$ & EMAS, 2010b \\
\hline Both will be replaced & $\begin{array}{l}\text { Increased standardisation } \\
\text { and fragmentation }\end{array}$ & $\begin{array}{l}5 ; 10 ; 12 ; 15 ; 17 ; \\
20-21\end{array}$ & $\begin{array}{l}\text { Brunsson and } \\
\text { Jacobsson, 2000b }\end{array}$ \\
\hline
\end{tabular}

Some interviewees rather pessimistically expected EMAS to die sooner or later (Interviews no. $11 ; 19)$. In this scenario, the trend of the early 2000s when EMAS validation numbers started declining continues until EMAS is given up by the authorities. Its future is a political question, i.e. it would depend on the EU and the national governments to keep it running (Interviews no. $1 ; 8 ; 10-11 ; 13-14 ; 16-18 ; 20)$. Whether it would be desirable for the authorities to keep EMAS alive through the 'drip-feed' (quotation off the record) of EMASfriendly programmes depends on its ability to become self-sustaining after a period of political backing. Here, EMAS is seen as a direct competitor of ISO 14001 (hypothesis (iii)) and expected to either lose the battle or be kept in it artificially. Some scholars argue that EMAS may have reached its goal by establishing high-quality EMSs in the industry and improving them over 10 to 20 years (Dyllick, 2007; Kollman and Prakash, 2002). Contrary to that, many interviewees stated that there was always room for improvement (Interviews no. 5; 17).

The second future scenario is that everyone abandons EMAS except the fan community. In this case, EMAS develops into an elitist club of those companies that explicitly wish to go beyond the mainstream standard ISO 14001 (Interviews no. 5; 8; 15-21). Here, EMAS is complementary with ISO 14001 and acts as additional distinction (hypothesis (ii)).

In the third scenario, EMAS becomes more relevant for SMEs and non-industrial organisations (Interviews no. 1, 5, 17, 21). The stabilisation of validation numbers in the mid2000s was mainly due to the increase in EMAS-validated SMEs, as well as charities, churches, and schools (EMAS, 2010b). In this scenario, EMAS backs out of competition with ISO 14001 which then becomes the only standard for the industry. It is not entirely clear 
whether this supports the complementarity hypothesis (ii) since the two standards might simply become independent rather than complementary. This would be true if SMEs and nonindustrial organisations would not get ISO 14001-certified at all.

\subsubsection{THREE SCENARIOS FOR ISO 14001}

Also for ISO 14001 three scenarios were repeatedly suggested. In the first scenario, ISO 14001 further increases its dominance as a quasi-mandatory minimum requirement for business relations (supporting hypothesis (iii)), similar to the quality standard ISO 9001 which is ISO's best-selling standard (Interviews no. $1 ; 4 ; 6 ; 10 ; 13 ; 16-17 ; 19$ ). After a steep rise, the Rogers curve of ISO 14001 adoption would be expected to level off eventually. In Germany, this point has not been reached as figure 3 shows.

***insert figure 3 about here $* * *$

The second scenario goes beyond the first in so far as ISO 14001 becomes more ambitious and more similar to EMAS until EMAS becomes redundant (supporting hypothesis (iii)). Although this may not seem likely at present, the Future Challenges Study Group under the Technical Committee 207 has been discussing legal compliance and environmental performance improvement, as well as how to integrate ISO 14001 in broader sustainability management (Interview no. 13).

The third scenario for ISO 14001 sees it replaced by a plethora of new standards which are structured similarly but address different sub-topics in more depth. The new energy management standard EN 16001 that was created by the European standardisation organisation (CEN) in 2009 is interpreted as one example for a wider trend (Interviews no. 1; $4 ; 9-10 ; 15 ; 21)$. Most interviewees acknowledged more or less openly that ISO, DIN and CEN are driven by private economic interests (see also Jasch, 1994) in contrast to EMAS which is a public system. Consequently, new 'product innovations' are continuously put on the market (Interview no. 12). The interviewees were divided in judging this trend - while certifiers and standardisation organisations benefit from new standards on offer, companies see new cost factors, and EMAS supporters feel exposed to more competition. Either way, this fragmentation trend might eventually render ISO 14001 redundant (Interview no. 13).

\section{Discussion}


In this Section, the findings are discussed with regards to their implications for the two research questions. First, the drivers for EMAS validation and ISO 14001 certification are discussed regarding their explanatory power for the first question (why do companies adopt both EMS standards?). Regarding the second research question (are they better understood as complements or substitutes?), it is found that the answer might differ between the present and the future. Finally, implications for research are discussed.

\subsection{DRIVERS OF EMAS AND ISO 14001 ADOPTION}

One of the major results of this study is the reason why many companies have both standards in place: they are chosen for completely different reasons. Several factors that previous research has found to influence the uptake of EMS standards can be confirmed but most were only relevant for either EMAS or ISO 14001.

For ISO 14001 implementation, external factors are most important, i.e. requirements from business partners but also ratings and legal compliance. The organisational field is crucial and strong support is found for a tendency towards isomorphism (Brunsson and Jacobsson, 2000a; DiMaggio and Powell, 1983; Rogers, 1995). Although normative pressure did not play a role in the diffusion of ISO 14001, coercive pressure was clearly there - first by the VDA and later among the upper to medium levels of the supply chain. Mimetic pressure was particularly strong among the high-price car producers for whom reputation is crucial.

Hardly any support was found for the influence of the institutional environment of firms, i.e. public agencies or stakeholders, in the case of both EMAS and ISO 14001. Regulatory relief was found to play a role for EMAS adoption but it was by far not as decisive as some researchers have suggested (Glachant, 2001; Wätzold et al., 2001). Moreover, all firms said that there was no significant demand for EMS standards by stakeholders, particularly not for the environmental statement required under EMAS. Many stated that the only parties to express interest in EMS standards were the public bodies in charge and scholars of environmental management. Therefore, this study finds no support for the importance of stakeholder pressure from the institutional field as suggested in the literature (Bansal and Bogner, 2002; Perkins and Neumayer, 2004; Potoski and Prakash, 2004). One important exception is the role of reputation as suggested by Delmas and Terlaak (2001) which is clearly confirmed by the differences in motivation between car manufacturers and their less visible suppliers. Interestingly, the reputational effect of EMAS seems to work backwards: while implementing EMAS does not bring reputational gains with it, abandoning it is feared to 
result in reputational damage. Some interviewees said that EMAS adoption seemed to have a trust-building effect and had improved their relationship with the authorities (Interviews no. $3 ; 7 ; 19)$ which is more than what former research suggests (e.g. Bracke and Albrecht, 2007). This study cannot confirm that firms pursue EMS standards in order to avoid future regulation because not one interviewee confirmed this. This is unlikely due to interviewer bias since interviewees openly discussed other politically sensitive issues. According to Corbett and Kirsch (2000), adopted standards may serve as preparation for new standards. Part of the reason why firms keep both EMS standards may be to facilitate the certification process of the emerging energy management system standards. In the interviews, this was not described as a main driver for implementation but it is possibly one reason for maintaining them.

As regards internal factors, Kitchell (1995) suggests that corporate culture can explain innovation adoption. This is supported by this study since the perception of the benefits of EMS adoption and consequently the adoption of EMAS seems to be directly dependant on corporate culture. For instance, the fan community companies are convinced that EMAS is the right system to have, and both the fan community and the win-win proponents expect environmentally friendly investment to pay off. The influence of key people played a role in five firms (Interviews no. $3 ; 5 ; 6 ; 8 ; 9$ ) of different categories. These individuals exert significant influence which indicates that environmental champions (Bansal, 2003) have an important role to play in the context of EMS standard adoption.

\subsection{THE RELATIONSHIP BETWEEN EMAS AND ISO 14001}

The typology of corporate cultures distinguishes companies that will continue EMAS in almost any case (fan community) from those who may well abandon it (rational calculators) and those whose decision will depend on incentive systems set up by policy-makers (winwin). The relationship between the two standards is perceived differently in each group. The fan community perceives EMAS as a distinction additionally to ISO 14001 certification; the rational calculators see direct competition between the standards which will be won by ISO 14001; and the win-win firms hold differentiated views. An interim result is therefore that the perception of this relationship strongly depends on the corporate culture.

Taking on a broader, industry-wide perspective, it seems that the relationship of ISO 14001 and EMAS is one of direct competition at the moment, and EMAS is widely believed to be losing this battle. This is suggested by Bracke and Albrecht (2007) and is supported by interviewee statements (Interview no. 11;19) as well as by the declining numbers of EMAS 
uptake within the industry while ISO 14001 adoption is still on the rise. However, it seems that different trends are going on which might transform this situation of competition into one of complementarity as suggested by Delmas (2002) and Delmas and Montiel (2008). In the future, EMAS may move away from direct competition by becoming a distinction for only a few, or by focusing on SMEs and non-industrial organisations. To answer the second research question, hypothesis (iii) is supported by more evidence, but things may develop further in direction of hypothesis (ii).

\subsection{MORE GENERAL THEORETICAL IMPLICATIONS}

ISO 14001 is an example of how standards can become de-facto mandatory when they are institutionalised (Brunsson and Jacobsson, 2000a; DiMaggio and Powell, 1983; Rogers, 1995). Triggered by the VDA in the 1990s, ISO 14001 has become established as a minimum standard that companies demand from their suppliers and which is decided upon at the highest corporate level. Why has the same not happened with EMAS? One explanation is provided by Rogers (1995) who describes a negative relation between uptake and stringency. EMAS goes beyond ISO 14001 in various aspects and requires truly voluntary commitment which may be part of the reason why it is outcompeted by ISO 14001 .

Bracke and Albrecht's (2007) description of how the perception of EMAS in Germany shifted from enthusiasm to disillusionment is partly confirmed by this study: EMAS has now been in place for such a long time that it is either just taken for granted, or companies indeed felt they had got 'stuck' with it.

The argument by Kollman and Prakash (2002) and Dyllick (2007) that low-hanging fruits may soon be gone and that efficiency gains had been mostly exploited, was discussed and rejected in the interviews (Interviews no. $5 ; 7 ; 12 ; 17$ ). Some recognised diminishing returns to scale (Interviews no, 7-8) but not one interviewee said that this would prohibit further improvement. Instead it seems that the win-win perspective has to a large extent swept over to corporate environmental departments. According to interviewee no. 5, 'environmental protection actually always pays off!'

The concept of sustainability requires a more holistic approach of which EMSs are just one part. The standard ISO 26001 might develop to become the overall system into which EMS standards are integrated (Interviews no. 4; 11; 19). Quite a few environmental managers said that such an integrative standard would be desirable and would support their efforts to move towards sustainability (Interviews no. $1 ; 10 ; 15 ; 19-20$ ). This might mean that the focus on 
EMS is somewhat outdated since corporate management has now started to address the sustainability challenge (Schaltegger and Wagner, 2011).

\section{Conclusion}

This study confirms several existing research findings but often only for either EMAS or ISO 14001. In the case of ISO 14001, an institutionalisation process is observed, and the importance of the organisational field is confirmed, particularly with regard to coercive and mimetic pressures towards isomorphism. In the case of EMAS, the critical role of corporate culture and influential individuals is more than obvious. The importance of the institutional environment can not be confirmed for EMAS adoption: stakeholder pressure seems to be mostly absent and regulatory relief never played an important role for corporate decisionmaking. However, the degree to which firms depend on reputation is an important driver for win-win firms and rational calculators to keep EMAS in place.

Regarding the first research question, it is found that the decisions about the two standards are motivated completely differently. While ISO 14001 has developed into a quasi-mandatory minimum requirement of global reach, EMAS has remained a truly voluntary standard aimed at the improvement of environmental performance. Although hypothesis (iii) might be describing the present situation correctly as one of direct competition in which EMAS and ISO 14001 act as substitutes, the future might well be closer to hypothesis (ii) in which the two standards are complementary. ISO 14001 would then further develop as a global industrial standard while EMAS would become a premium standard or a standard for SMEs and non-industrial organisations.

These results have some interesting implications. First, since EMAS uptake is not motivated by regulatory relief, policy makers are well advised to focus on raising awareness in order to influence internal motivation rather than granting regulatory relief. Second, ISO 14001 may have an important role to play by establishing a minimum standard for environmental management in firms worldwide. However, the standard might only be one among more and more other environmental imperatives such as environmental reporting or substance bans that are expected to become daily business in the move towards corporate sustainability.

If one is to generalize from this study, the adoption of standards can be motivated by either internal or external factors. If standards adoption is internally motivated it is likely only one part of an ambitious environmental strategy. Yet, this might only occur in rather few firms 
with a distinct corporate culture. Standards might be more likely to be adopted by a majority of companies if pressures for isomorphism are at work, such as coercive requirements from clients or industry associations, as in the case of ISO 14001. This wider adoption might also increase the risk for a standard lock-in. In further research, it would be interesting to see if adoption of ambitious standards aiming at absolute improvement (such as EMAS) is generally motivated by internal factors while more formal standards are rather motivated by external pressure, as this study suggests (see also Müller et al., 2009). Further, the relation between EMAS and ISO 14001 in other sectors and countries may well differ and would be an interesting research topic, e.g. in Spain and Italy where EMAS validations have been increasing at an impressive speed.

\section{ACKNOWLedgements}

I owe thanks to Richard Perkins who has supervised this research at LSE for his constructive feedback, as well as to Frank Figge whose comments on previous drafts were very helpful. I would also like to thank all interviewees from whose expertise and openness this study has greatly benefitted, as well as two anonymous reviewers. 


\section{References}

Banerjee, S.B., 2002. Corporate environmentalism: the construct and its measurement. Journal of Business Research 55, 177-191.

Bansal, P., 2003. From Issues to Actions: The Importance of Individual Concerns and Organizational Values in Responding to Natural Environmental Issues. Organization Science 14, 510-527.

Bansal, P., Bogner, W.C., 2002. Deciding on ISO 14001: economics, institutions, and context. Long Range Planning 35, 269-290.

Bracke, R., Albrecht, J., 2007. Competing environmental management standards: how ISO 14001 outnumbered EMAS in Germany, the UK, France, and Sweden. Environ. Plann. C 25, 611-627.

Brunsson, N., Jacobsson, B., 2000a. Following standards, in: Brunsson, N., Jacobsson, B. (Eds.), A world of standards. Oxford University Press, Oxford, New York, pp. 127-137.

Brunsson, N., Jacobsson, B., 2000b. The Contemporary Expansion of Standardization, in: Brunsson, N., Jacobsson, B. (Eds.), A world of standards. Oxford University Press, Oxford, New York, pp. 1-19.

Corbett, C.J., Kirsch, D.A., 2000. ISO 14000: an agnostic's report from the front line. ISO 9000+ ISO 14000 News 9, 4-17.

Delmas, M.A., 2002. The diffusion of environmental management standards in Europe and in the United States: An institutional perspective. Policy Sciences 35, 91-119.

Delmas, M.A., Montiel, I., 2008. The diffusion of voluntary international management standards: Responsible Care, ISO 9000, and ISO 14001 in the chemical industry. Policy Studies Journal 36, 65-93.

Delmas, M.A., Terlaak, A.K., 2001. A framework for analyzing environmental voluntary agreements. California Management Review 43, 44-63.

DESTATIS, 2012. Inlandsproduktsberechnung. https://www.destatis.de/DE/ZahlenFakten/GesamtwirtschaftUmwelt/VGR/Inlandsprodukt/ Tabellen/BWSBereichen.html. Accessed April 9, 2012.

DIHK, 2010. EMAS-Statistik des DIHK. http://www.emas.de/fileadmin/user_upload/04_ueberemas/Statistik/EMAS-TN-AnzahlBundeslaender-DIHK.pdf. Accessed August 15, 2010.

DiMaggio, P.J., Powell, W.W., 1983. The iron cage revisited: Institutional isomorphism and collective rationality in organizational fields. American sociological review 48, 147-160.

Dyllick, T., 2007. Umweltmanagementsysteme: eine Bilanz. Umwelt Perspektiven. http://www.alexandria.unisg.ch/export/DL/39103.pdf.

Dyllick, T., Hockerts, K., 2002. Beyond the business case for corporate sustainability. Bus. Strat. Env 11, 130-141.

EMAS, 2010a. EMAS Statistics, Evolution of Organisations and Sites. Quarterly Data 30/06/2010. http://ec.europa.eu/environment/emas/pictures/Stats/201004_EVOLUTION_Graph.JPG. Accessed August 18, 2010.

EMAS, 2010b. EU Register. Search engine for EMAS registrations. http://ec.europa.eu/environment/emas/register/. Accessed August 20, 2010.

Epstein, M.J., Roy, M.-J., 1998. Managing corporate environmental performance: A multinational perspective. European Management Journal 16, 284-296.

Franken, R., Franken, S., 2011. Integriertes Wissens-und Innovationsmanagement. Gabler Verlag.

Glachant, M. (Ed.), 2001. Implementing European environmental policy. The impacts of directives in the member states. Edward Elgar, Cheltenham, Northampton. 
Greve, H.R., 1998. Managerial cognition and the mimetic adoption of market positions: What you see is what you do. Strategic Management Journal 19, 967-988.

Hahn, T., Figge, F., Pinkse, J., Preuss, L., 2010. Trade-offs in corporate sustainability: you can't have your cake and eat it. Bus. Strat. Env 19, 217-229.

Hillary, R., Thorsen, N., 1999. Regulatory and self-regulatory measures as routes to promote cleaner production. Journal of Cleaner Production 7, 1-11.

Hoffman, A.J., 2001. From heresy to dogma. An institutional history of corporate environmentalism, Expanded. Stanford University Press, Stanford, Calif.

Holliday, C.O., Schmidheiny, S., Watts, P., 2002. Walking the talk: The business case for sustainable development. Berrett-Koehler Publishers.

ISO, 2005. ISO Survey of Certifications 2005.

http://www.iso.org/iso/iso_catalogue/management_standards/certification/the_iso_survey. htm. Accessed August 22, 2010.

ISO, 2008. ISO Survey of Certifications 2008, Geneva. http://www.iso.org/iso/survey2008.pdf.

Jasch, C., 1994. The role of standardization in promoting cleaner production and environmental management. Journal of Cleaner Production 2, 197-199.

Khanna, M., Anton, W.R., 2002. Corporate environmental management: regulatory and market-based incentives. Land Economics 78, 539-558.

Kitchell, S., 1995. Corporate culture, environmental adaptation, and innovation adoption: A qualitative/quantitative approach. Journal of the Academy of Marketing Science 23, 195205.

Kollman, K., Prakash, A., 2001. Green by choice? Cross-national variations in firms' responses to EMS-based environmental regimes. World Politics 53, 399-430.

Kollman, K., Prakash, A., 2002. EMS-based environmental regimes as club goods: examining variations in firm-level adoption of ISO 14001 and EMAS in UK, US and Germany. Policy Sciences 35, 43-67.

Kvale, S., 1996. Interviews: An Introduction to Qualitative Research Interviewing. Sage Publications, Inc, Thousand Oaks, California.

Maxwell, J.W., Lyon, T.P., Hackett, S.C., 2000. Self-regulation and social welfare: The political economy of corporate environmentalism. Journal of Law and Economics 43, 583-618.

Moon, S., DeLeon, P., 2005. The patterns of institutional interaction and ISO 14001 adoptions. Comparative Technology Transfer and Society 3, 35-57.

Müller, M., dos Santos, V., Seuring, S., 2009. The Contribution of Environmental and Social Standards Towards Ensuring Legitimacy in Supply Chain Governance. Journal of Business Ethics 89, 509-523.

Neumayer, E., Perkins, R., 2004. What Explains the Uneven Take-Up of Iso 14001 at the Global Level? A Panel Data Analysis. Environ. Plann. A 36, 823-839.

Oliver, C., 1991. Strategic Responses to Institutional Processes. The Academy of Management Review 16, 145-179.

O'Neill, H.M., Pouder, R.W., Buchholtz, A.K., 1998. Patterns in the diffusion of strategies across organizations: Insights from the innovation diffusion literature. The Academy of Management Review 23, 98-114.

Perkins, R., Neumayer, E., 2004. Europeanisation and the uneven convergence of environmental policy: explaining the geography of EMAS. Environ. Plann. C 22, 881897. 
Perkins, R., Neumayer, E., 2010. Geographic variations in the early diffusion of corporate voluntary standards: comparing ISO 14001 and the Global Compact. Environ. Plann. A 42, 347-365.

Porter, M.E., van der Linde, C., 1999. Green and Competitive: Ending the Stalemate. Journal of Business Administration and Policy Analysis 73, 120-134.

Potoski, M., Prakash, A., 2004. Regulatory Convergence in Nongovernmental Regimes? Cross-National Adoption of ISO 14001 Certifications. J of Pol 66, 885-905.

Rogers, E.M., 1995. Diffusion of innovations, 4th ed. Free Press, New York.

Schaefer, A., 2007. Contrasting Institutional and Performance Accounts of Environmental Management Systems: Three Case Studies in the UK Water \& Sewerage Industry. Journal of Management Studies 44, 506-535.

Schaltegger, S., Burritt, R., 2000. Contemporary environmental accounting: issues, concepts, and practice. Greenleaf Publishing.

Schaltegger, S., Wagner, M., 2011. Sustainable entrepreneurship and sustainability innovation: categories and interactions. Bus. Strat. Env 20, 222-237.

UBA, 2010. Entwicklung der THG-Emissionen in Deutschland nach Sektoren. http://www.umweltbundesamt.de/uba-info-presse/2010/pdf/pd10-003_bild1.pdf. Accessed April 8, 2012.

UBA, 2011. Umweltökonomie und Umweltmanagement - Umweltmanagementsysteme weltweit. http://www.umweltbundesamt.de/umweltoekonomie/ums-welt.htm. Accessed August 18, 2010.

Wätzold, F., Bültmann, A., Eames, M., Lulofs, K., Schucht, S., 2001. The implementation of EMAS in Europe: a case of competition between standards for environmental management systems, in: Glachant, M. (Ed.), Implementing European environmental policy. The impacts of directives in the member states. Edward Elgar, Cheltenham, Northampton, pp. 134-177.

Weizsäcker, E. von, 2010. Factor five: transforming the global economy through $80 \%$ improvements in resource productivity: a report to the Club of Rome. Earthscan/James \& James.

Young, W., Tilley, F., 2006. Can businesses move beyond efficiency? The shift toward effectiveness and equity in the corporate sustainability debate. Bus. Strat. Env 15, 402415.

Zito, A.R., Egan, M., 1998. Environmental management standards, corporate strategies and policy networks. Environmental Politics 7, 94-117. 
> Corporate decisions about implementing ISO 14001 are motivated by external factors. > Decisions about EMAS are motivated by internal factors. > Company classification as fan community, rational calculators, and win-win proponents. > EMAS and ISO 14001 are likely in a situation of direct competition at present. > This situation may well turn into complementarity in the future. 
Fig. 1: ISO 14001 worldwide, and ISO 14001 and EMAS in Europe 2000-2010

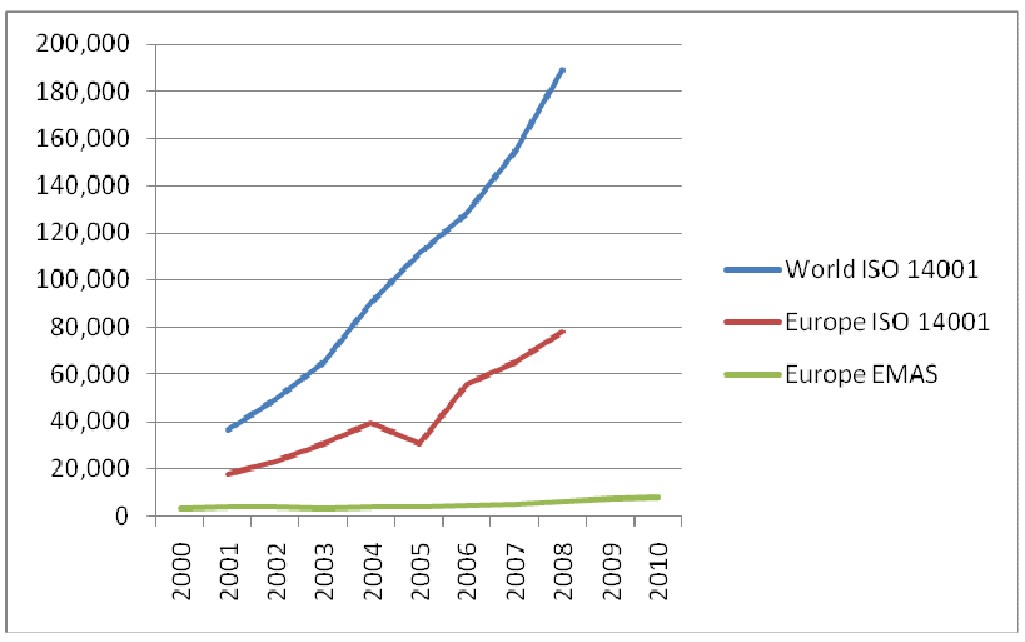

Data sources: EMAS, 2010a; ISO, 2005, 2008 
Fig. 2: The expected adoption curve for hypothesis (iii), substitution

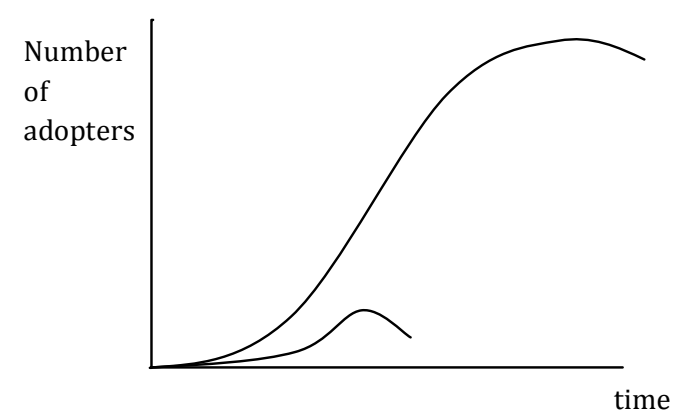

Based on: Rogers, 1995 


\section{Fig. 3: Uptake of EMAS and ISO 14001 in Germany}

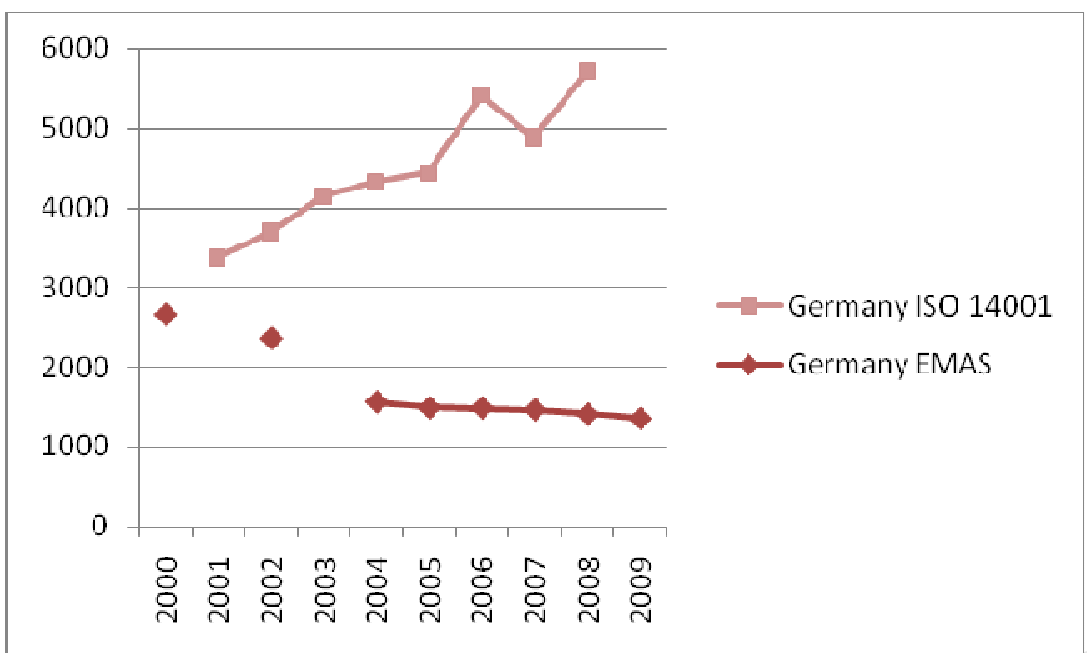

Data sources: DIHK, 2010; ISO, 2005, 2008 